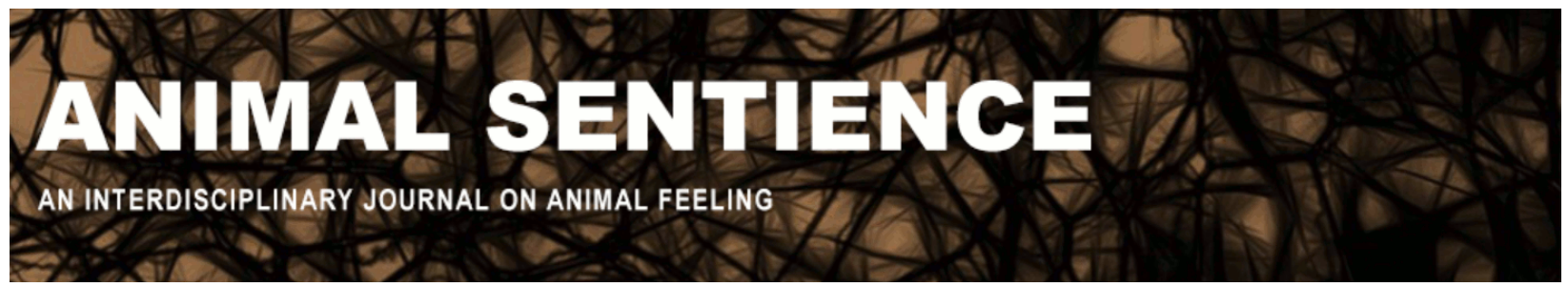

Woodruff, Michael L. (2018) Sentience in fishes: More on the evidence. Animal Sentience 13(16)

DOI: $10.51291 / 2377-7478.1313$

Date of submission: 2018-03-02

Date of acceptance: 2018-03-12

(c)

This article has appeared in the journal Animal

Sentience, a peer-reviewed journal on animal

cognition and feeling. It has been made open access,

free for all, by WellBeing International and deposited

in the WBI Studies Repository. For more information,

please contact

wbisr-info@wellbeingintl.org.

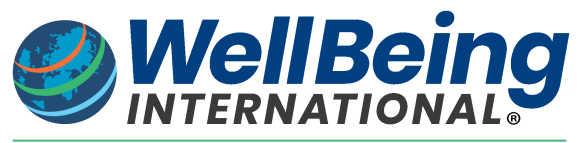

SOLUTIONS FOR PEOPLE, ANIMALS AND ENVIRONMENT 


\title{
Sentience in fishes: More on the evidence
}

Response to Commentary on Woodruff on Teleost Consciousness

\author{
Michael L. Woodruff \\ Departments of Biomedical Sciences and Psychology \\ East Tennessee State University
}

\begin{abstract}
In my target article, I argued that the brains of ray-finned fishes of the teleost subclass (Actinopterygii) are sufficiently complex to support sentience - that these fishes have subjective awareness of interoceptive and exteroceptive sense experience. Extending previous theories centered on the tectum, I focused on the organization of the fish pallium. In this Response to the commentaries, I clarify that I do not propose that the fish pallium is, or must be, homologous to the mammalian neocortex to play a role in sentience. Some form of a functionalist approach to explaining the neural basis of sentience across taxa is probably most appropriate. However, what is known about the neural correlates of consciousness in humans is adequate to provide a starting place for investigation of the correlates of sentience in other animals, including fishes. Ultimately, though, hypotheses and experiments to evaluate anatomical and physiological correlates specific to sentience in fishes will be necessary.
\end{abstract}

Michael L. Woodruff is Professor Emeritus of Biomedical Sciences and of Psychology at East Tennessee State University. Author of more than 120 professional publications, his research interests include cognitive neuroscience and the philosophy of mind. www.researchgate.net/profile/Michael Woodruff3/info

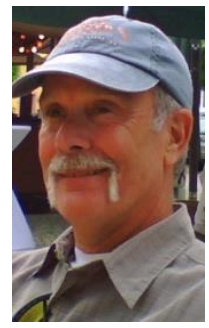

\section{DOES NEUROSCIENCE HAVE ANSWERS ABOUT CONSCIOUSNESS?}

I thank the commentators for providing an interesting, insightful and diverse set of commentaries on the target article. I will begin my Response by discussing the objection raised by Gutfreund (2017a), who summarizes his objection with the following words: "At the moment the only reason to justify inferring consciousness in an animal is that we are conscious. So, the only way to resolve questions about consciousness in animals is by resolving our consciousness first." He then denies that any progress is being made in achieving this resolution. However, extrapolating from the discovery of the neural basis of some adaptive behaviors in weakly electric fish and barn owls, he seems to believe that a complete understanding of the neural basis of complex cognitive functions, such as attention and decision making, is well along. Consciousness will not be needed for this understanding (Gutfreund 2017b). From these beliefs he argues that, logically, the more we know about the neural basis of behaviors in any given species, the less likely it is that that species is conscious. He calls this the "neuroethological paradox of animal consciousness" and concludes: "This growing gap between our advanced understanding of animal brains and our lack of understanding of consciousness in animals should, in line with the above paradox, reduce our 
confidence in the idea of widespread consciousness across animal species" (Gutfreund 2017b, p. 197).

The foundation of Gutfreund's argument is the assumption that no progress has been made in understanding the neural basis of consciousness ${ }^{1}$ in humans. It is incontestable that we do not have the mechanistic account of the neural basis of consciousness Gutfreund demands, but over the last two decades, notable progress has been made in identifying in humans what Crick and Koch (2003; Koch 2012) call the neural correlates of consciousness (NCC), and what Dehaene (2014) refers to as signatures of conscious thought. Thus, I submit that the epistemic question is not whether there is a mechanistic explanation of consciousness but whether it is legitimate to infer consciousness in a nonhuman species from the available data about human NCC.

In the target article, I used an extended argument from analogy (Andrews 2015, pp. 62-68) to suggest that the best explanation for sentience in fishes gives an affirmative answer to this question. In later sections of this Response, I will discuss some of the behavioral and neurobiological properties I used as the analogies in my argument. Here I want to respond to Gutfreund by pointing out some of the consequences of accepting his conclusion that no progress has been made in understanding the neural basis of consciousness.

\subsection{Neuroscience has no answers to consciousness: Pragmatic consequences}

In the title of his commentary, Gutfreund claims that "neuroscience has no answers" to the problem of consciousness. This claim has at least two pragmatic consequences. First, Gutfreund would seem to be logically compelled to accept that efforts to use brain-imaging techniques, such as positron emission tomography (PET) and functional magnetic resonance imaging (fMRI), to improve differential diagnoses in patients with disorders of consciousness (DOC) are futile. To me this seems irresponsible. Making an accurate discrimination among DOC patients with vegetative state/unresponsive wakefulness syndrome (VS/UWS), a minimally conscious state (MCS), or those with locked-in syndrome (LIS) is crucial to an appropriate clinical management plan, and, in the extreme, to making decisions concerning continuation or termination of life support. Systematic clinical examination based on behavioral signs, such as purposeful behaviors, is vitally important to differential diagnosis among DOC patients, but clinicians acknowledge that the absence of behavioral signs associated with the various categories of DOC does not provide a reliable diagnosis of the presence or absence of consciousness.

Over the past decade, controlled clinical studies have found that differences in distribution of PET and fMRI activity across brain regions, while not definitive (Boly et al. 2013), are useful in diagnosing the difference among DOC patients, particularly between those with either VS/UWS or MCS (Giacino et al. 2014; Gosseries et al. 2014; Laureys and Schiff 2012). As Gosseries et al. (2014) note, the results of these studies and their interpretation have been strongly informed by theories of the neural basis of consciousness in humans and continue to inform these theories in turn (e.g., Dehaene 2014). Countering Gutfreund's assertion that we know nothing about the neural basis of human consciousness,

\footnotetext{
${ }^{1}$ As I indicated in the target article, I follow Allen and Trestman (2016) and equate sentience with phenomenal consciousness. For that reason, and because Gutfreund and many of the other commentators use consciousness in their comments, I will use consciousness and sentience interchangeably in my Response.
} 
this work demonstrates that there is an existing and useful interaction between empirically based theories of the neural basis of consciousness and clinical applications.

Second, laws and regulations designed to protect animals from practices which cause them distress and pain are generally based on the attribution of sentience. It may be that these regulations need to be extended to species not now covered, including fishes (Balcombe 2016) and crustaceans (Birch 2017). Denying that animals are sentient based on rejection of the plausible existence of behavioral and neurobiological analogies with humans would most certainly hamper these efforts, and, in a worst-case scenario, could lead to a rollback of existing regulations. ${ }^{2}$

The empirical evidence supporting any of the existing theories of consciousness is admittedly incomplete, and, ideally, we should not make leaps from evidence to theory without complete empirical support from experimental research. However, as the philosopher of science Heather Douglas (2000; 2009) has concluded, in many cases, the importance for practice and policy of the problems under investigation not only permits but requires that a theory be accepted as plausible even in the absence of a complete mechanistic explanation. Storm et al. (2017) concurred with this conclusion in their recent review of progress in isolating NCC in humans, non-human primates, and rats. Referencing Gutfreund (2017b) they write (p. 10888), "there is an increasing need to come up with a neuroscientific account of animal consciousness, not necessarily providing definitive answers but rather a 'best estimate' facilitating rational decisions on issues of great societal relevance, such as ritual slaughter and pain mitigation in animal health care."

\section{SELECTIVE ATTENTION: BOTTOM-UP AND TOP-DOWN PROCESSING}

Stauffer (2017), accuses me of being promiscuous in the use of selective attention as a criterion for sentience. I did not intend this and stated (Woodruff 2017, p. 5) that: "Sentience and selective attention are generally not considered to be the same process, and evidence indicates that either can be present without the other." But I may have blurred the distinction by stating: "However, in the absence of selective attention, the contents of sentience required to produce specific actions necessary for survival, such as finding food or avoiding a predator, are absent." Whether selective attention is necessary for consciousness is still debated. Some researchers in this area insist that it is necessary (e.g., Cohen et al. 2012; Dehaene et al. 2006). However, the weight of the evidence increasingly suggests that selective attention can exist without consciousness, and consciousness can exist in the absence of selective attention (e.g., van Boxtel et al. 2010). In addition, as Stauffer points out, citing Johnston and Dark's distinction (1986) between external and internal selective attention, selective attention is not

\footnotetext{
${ }^{2}$ In the last paragraph of his article in Trends in Neurosciences, Gutfreund (2017b) acknowledges this concern, but discounts it, writing: "Some readers of this article will be alarmed that my criticism of scientific claims for widespread sentiency in the animal kingdom can lead to unethical objectification of animals. I argue the contrary, it is the scientific attempts to divide animals into those that are conscious and those that are not that can lead to objectification of animals. My claim is that any such attempt is premature, including theories that assign consciousness exclusively to great apes. Animals should be treated with respect and compassion because this is the most sensible and humane thing to do, irrespective of findings emerging from laboratories studying animal brains and behaviors." Having spent the greater part of four decades witnessing efforts in the US to improve the treatment of laboratory animals, this view strikes me as naïve.
} 
a unitary process. Johnston and Dark's distinction is compatible with the distinction made by others between bottom-up and top-down attentional processes (van Boxtel et al. 2010).

Attentional selection can be based either on bottom-up processing driven by factors related to external stimuli, or on top-down processing using endogenous cognitive processes such as memory. Either type of processing can be conscious or unconscious. Whether or not consciousness is involved appears to depend on the function involved in the behavior under consideration. For example, according to the classification for humans outlined by Christof Koch and his colleagues (van Boxtel et al. 2010), in visual search, the pop-up phenomenon is an example of the bottom-up process associated with consciousness, while working memory is an example of a top-down process associated with consciousness.

Pop-out was described for visual search in archer fish in the target article. I will describe examples of experiments showing working memory in fishes below. I conclude from these examples that in fishes - as, presumably, in all mammals - sentience accompanies selective attention in some behaviors, but not others. Thus, I agree with Stauffer that unconscious selective attention can successfully guide behavior in fishes (as it does in humans), but I disagree that selective attention, whether it is external (bottom-up) or internal (top-down), is never associated with sentience in fishes.

On this view, sentience can be associated with some behaviors indicating bottom-up selective attention. That is, the attentional selection is not determined by endogenous cognitive processes but by features of the environmental stimuli. Following Gibson's (1979) ecological approach to perception, Favela (2017) argues that bottom-up, or external, selective attention is all that is needed for sentience in fishes. A complete reply to Favela would require a critique of Gibson's theory which is far beyond the scope of this Response. I will hence offer only one reflection: I wonder why, given his grounding in Gibson's theory, Favela would propose that phenomenal consciousness in fish exists at all. As he writes in his commentary: "instead of going inward into the mind to find additional information, ecological psychologists go outward into the environment." On Gibson's view, the affordances of environmental stimuli are adequate to guide adaptive behavior. For example, I do not have to be consciously aware of the percept "handle" to grasp it and lift a coffee cup to my mouth. All the information that is needed to accomplish this behavior is in the stimulus of the cup. Gibson's ecological approach, then, is generally used to negate any theory that invokes the role of cognitive processing, let alone sentience, in perception (Costall 1984). I accordingly doubt that ecological psychology, at least as traditionally formulated by Gibson, has much, if anything, to contribute to the understanding of sentience in fishes.

\section{BEHAVIORAL DATA AND SENTIENCE}

In the target article, I emphasized the anatomy and physiology of the fish brain. My intention was to extend the work of Feinberg and Mallatt (2016) and Braithwaite (2010), among others, which associated neurobiology with sentience in fishes. However, although some neurophysiological correlates of sentience that do not depend on verbal or behavioral "report" have been proposed for humans and non-human primates (Storm et al. 2017), behavioral evidence is generally regarded as fundamental to attributing sentience. I accordingly presented selected examples of behaviors as evidence of sentience in fishes. Some commentators agreed and added additional examples. Others disagreed with my interpretations. 


\subsection{Can observations be generalized across species?}

Allen-Hermanson (2017) questioned the validity of the behavioral examples I discussed. He expressed a general concern as to the extent to which behavioral observations can be generalized among species. Stauffer also raised this question. Caution should be used when extrapolating research results from one species to another. Preferably, whether a behavior observed in one species of fish can be generalized to other fish species is an issue to be resolved through appropriate experimentation. For example, goldfish exhibit trace conditioning (Portavella et al. 2004; Vargas et al. 2009). Can this finding be generalized to cod and halibut? Experiments have confirmed the presence of trace conditioning in these species (Nilsson et al. 2008; 2010).

If direct experimental evidence is weak, however, a theoretical model presented by Brown (2017) offers an evolutionarily defensible approach to generalizing behavioral results across species. He calls this the phylogenetic approach. Although not as strong as extensive direct experimental demonstration of generalizability, this approach can legitimately assist in formulating policy decisions if they must be made in the absence of complete datasets. It also offers predictive power for generating hypotheses to guide experiments.

\subsection{Transitive inference in cichlids as an indicator of sentience}

Expressing a specific concern, Allen-Hermanson doubts that the experiment by Grosenick et al. (2007) demonstrates that male cichlids exhibit transitive inference. According to the supplemental material accompanying the article by Grosenick et al., the bystander fish and combatant fish were housed together prior to the experiment. Allen-Hermanson proposes that associative learning during this pre-experimental, group-housing period enabled the bystander fish to learn the social rank of the combatant fish. During the experimental tests, then, the bystander fish responded to these pre-experimentally learned cues when they chose to pair with weaker combatant fish. This explanation disagrees with the interpretation that inference was made from naïve observations of the outcome of fights among combatants made during the experimental sessions (Droege and Braithwaite 2014; Grosenick et al. 2007; Woodruff 2017). This disagreement is one that can be resolved empirically. I am disinclined to change my interpretation in the absence of evidence from appropriately designed experiments.

\subsection{Working memory in fish}

I did not discuss working memory in the target article. Taschereau-Dumouchel et al. (2017) point out that working memory has been associated with consciousness (e.g., Prinz 2000). Can it be shown in fish? The answer is yes. But, this yes depends upon acceptance of a definition of working memory that can be applied to animals. The concept of working memory is often associated with Baddeley (1986), who proposed it as a form of active shortterm memory in which auditory, particularly verbal, representations (phonological loop) and representations of visual space (visual-spatial scratchpad) were manipulated by a central executive with the help of selective attention. Baddeley's model was developed to understand one aspect of human memory processing. Whether, in its specifics, it can be applied to animals can be debated. However, the concept of working memory predates Baddeley's 
formulation. Miller et al. (1960) proposed working memory as a limited capacity cognitive system that temporarily holds information for processing to guide decision-making and behavior. Several simple tasks are accepted as tests of working memory, as so defined, in rats (e.g., Dudchenko 2004; Olton et al. 1979; Woodruff et al. 1993). Adaptations of these tasks to the aquatic environment indicate the presence of working memory in fish. For example, Ohnishi (1974) found that goldfish could learn to discriminate the position of a reinforcement between arms of a Y-maze even when a delay was introduced between forced exposure to the reinforcement and arm choice, and Creson et al. (2003) demonstrated working memory in black mollies using a non-reinforced alternation procedure in a T-maze. As Creson (2017) notes in his commentary, this experiment is particularly interesting because its design permitted dissociation between working memory and spatial memory in the same subjects.

\subsection{Temporal representation, behavioral flexibility and sentience}

In her commentary, Droege (2017) offers a theory for identifying consciousness that emphasizes flexible responding and representation of the "present moment." In her words: "Consciousness is only necessary to be able to flexibly respond, that is, to respond differently to a situation in order to achieve a goal. Consciousness allows dynamic changes in action or the goal in response to situational demands." I suggest that Droege's theory may be useful in defining behaviors relevant to application of the Animal Sentience Precautionary Principle developed by Birch (2017).

To apply her theory, Droege and her colleague Brathwaite (Droege and Braithwaite 2014) propose four methodological ways to identify flexible responding operationally. The first way is inherent in the concept of flexible responding as well as in the other three ways. Differential response to the environment must be present. To meet its goals (e.g., safety from attack, procurement of food) in a novel situation, an animal may not be able to rely on an existing algorithm, such as prior associative conditioning, to produce the most effective behavior. Behavioral flexibility is therefore needed; it is demonstrated when an animal infers future conditions in response to novel situations based on representation of multiple current stimuli and past information.

This is the second method Droege and Braithwaite (2014) propose. They cite the study by Grosenick et al. (2007) as an example of this way of identifying consciousness, rejecting the interpretation, as I did, that the bystander fish chose to associate with the weaker combatant fish based on long-term memory. Rather, the observer fish inferred "the relative strength of the particular individuals in the specific current situation. Representation of the features in the world now is needed to respond appropriately" (Droege and Braithwaite 2014). In addition to inference, working memory was also involved in choosing the weaker fish after having observed the fights. As noted in the previous section, working memory is often also a process associated with consciousness.

The third way of demonstrating consciousness proposed by Droege and Braithwaite is the ability to manipulate the environment to accomplish goals. I refer the reader to their paper for examples of studies in which fish exhibit environmental manipulation.

The fourth indicator of behavioral flexibility "is the ability to represent both present features of the situation and features that are absent in the immediate stimulus" (Droege and Braithwaite 2014). Droege and Braithwaite use allocentric spatial memory to demonstrate this indicator of flexible behavior and, thus, consciousness. They emphasize that in spatial 
tasks the subject needs to predict not just where reinforcement can be found, but where reinforcement will not be found. For example, in the standard water maze used to test spatial memory in rats, the rat's spatial map includes not just that the platform is in one specific place in the tank, but that it is not in any other possible locations (e.g., Woodruff et al. 1992).

Droege and Braithwaite's argument for allocentric spatial memory as a way of demonstrating behavioral flexibility and thereby inferring sentience is consistent with my position in the target article and with the inclusion of allocentricity as a marker of consciousness by Seth et al. (2005). In addition, if allocentricity is a valid marker of sentience, it might be expected to generalize widely across families of fishes. This appears to be the case. Allocentricity has been demonstrated in goldfish (Cyprinidae; Durán et al. 2010), Siamese fighting fish (Osphronemidae; Roitblat et al. 1982), gobies (Gobiidae; White and Brown 2015) and black mollies (Poeciliidae; Creson et al. 2003).

\section{CONSCIOUSNESS AND ITS NEURAL CORRELATES IN FISH}

\subsection{P-consciousness or A-Consciousness?}

In the target article, I argued that fish are sentient. Following Allen and Trestman (2016), I equated sentience and phenomenal consciousness. Mikhalevich (2017) and Husband (2017) propose that, rather than phenomenal consciousness (P-consciousness), I have made an argument that fish have access consciousness (A-consciousness). I intend the contrary and thank them for identifying this problem.

The distinction between P-consciousness and A-consciousness is usually identified with Ned Block (1995; 2007; 2011). In Block's theory, P-consciousness has a large capacity, while A-consciousness has a limited capacity. P-conscious contents are qualitative and are not directly available to cognitive processing. Because P-conscious contents are not available to cognitive processing, they have no function. The contents of A-consciousness, on the other hand, are representational, not phenomenal, and function to influence cognitive processing. If, as Mikhalevich notes in her commentary, a fish had only A-consciousness, it would have no qualitative experiences. It would be, in Block's (1995) words, "a full-fledged phenomenal zombie" (p. 233). I submit that fish are not zombies and, in agreement with others (Dehaene 2014; Gilman 1997; Güzelderea and Aydedeb 1997; Mangan 1997; Mack et al. 2015; Mack et al. 2016; Noë 1997; Papineau 2007; Persuh et al. 2012), argue that there is good reason to reject Block's theory.

Block (1995; 2007; 2011) uses Sperling's (1960) classic study as one main source of support for his theory. Sperling explored the capacity of iconic memory 3 in humans. Sperling showed subjects a stimulus consisting of 3 rows of 4 letters and numbers for 0.5 seconds and asked them to recall as many of the 12 items as possible immediately upon offset of the stimulus. He found that they recalled an average of 4.3 items. Block takes this result to indicate the presence of limited capacity A-consciousness. However, subjects also typically

\footnotetext{
${ }^{3}$ The term iconic memory had not been introduced when Sperling conducted his classic experiment. He used the term immediate-memory span for visual stimuli in referring to the type of rapidly decaying sensory memory he manipulated in his experiments.
} 
stated that they "saw more items than they remembered." Block $(1995 ; 2007)$ takes this as evidence for the existence of P-consciousness as he defines it.

Sperling quantified the impression that "more is seen than is remembered" in another experiment. The stimulus in this experiment was also 3 rows of 4 letters and numbers presented for $0.5 \mathrm{sec}$. Immediately upon offset of the stimulus, a high-frequency tone, a midfrequency tone, or a low-frequency tone was sounded. The order of presentation of the tones was random. The subjects were instructed to report the letters in the upper row if the high tone sounded, the middle row if the mid tone sounded, or the lower row if the low tone sounded. Thus, in this "partial-report" procedure, the subjects were tasked with recalling only 4 items, not 12 items, a number within the capacity of iconic memory identified in the first experiments. The subjects recalled an average of 3.3 of the 4 items in the row associated with the tone's frequency. Because the subjects did not know which tone would be presented, accurate performance required that more items than the 4 in the row cued for recall be available at the time the tone was sounded. Sperling (1960) calculated that an average of 9.1 of 12 items are available to the subjects at the time of report. For Block these results demonstrate that P-consciousness has a capacity that "overflows conscious access" (Block 2007; 2011) and that P-consciousness is a pre-attentive, pre-experiential, non-reportable state with no function. Only A-consciousness contents are available to cognitive processing.

However, as Naccachea and Dehaene (2007) point out, some of the evidence Block uses to support the existence of P-consciousness - that is, the claim that "more is seen than is remembered" by subjects - itself relies on accepting a subjective experiential report. This strongly suggests that $\mathrm{P}$-consciousness influences cognitive processing and that there is only one consciousness, the contents of which include the overall phenomenal scene and individual phenomenal items within the scene, both of which are accessible (Papineau 2007). Accessibility is produced in Sperling's full report condition when top-down attentional processes amplify items (Koch and Tsuchiya 2007). These items are then recalled. Bottomup attention contributes to recall in the partial-report condition. This interpretation implies that P-consciousness is not pre-attentive and is supported by experiments using either Sperling's design or "change blindness" (Simons and Levin 1997) in which attentional load was manipulated. The results of these experiments indicate that attention plays a significant role in the accessibility of the contents of P-consciousness (Mack et al. 2015; 2016; Persuh 2012). In sum, this theory accounts for Sperling's observations without the necessity of postulating two separate consciousnesses. Rather, P-consciousness alone produces subjective experience.

In response to Taschereau-Dumouchel et al. (2017), I maintain that Pconsciousness (i.e., sentience) in fishes does not require higher-order thought and selfreflection. On my view, although their descriptions differ in detail, sentience in fishes is equivalent to what Feinberg and Mallatt (2016) call sensory consciousness, Merker (2007) calls core consciousness, and G. Edelman (1989; 2003) calls primary consciousness. Sentience in fishes includes, for example, the basic feeling of sensations such as color and pain, as well as bodily states associated with emotion. Further, it integrates memory with the need for adaptive action in present time (e.g., Droege). G. Edelman (2003) summarized an animal with this type of sentience (primary consciousness) in this way: "Such an animal with primary consciousness has no explicit narrative capability (although it has long-term memory), and, at best, it can only plan to deal with the immediate scene in the remembered 
present. Nonetheless, it has an advantage over an animal lacking such an ability to plan" (p. 5521). This seems a heuristically useful description of sentience in fishes.

\subsection{Subjective experience and subjective perspective}

LaFollette (2017) wants clarification concerning my use of "subjective experience." His inference that subjective experience, as I use it, identifies the locus of experience is correct. This locus can be thought of as a first-person perspective, but I am not implying that fish are in any way self-conscious. Sentience in fishes does not require the ability to monitor one's own cognitions. However, I maintain that a "scene in the remembered present" is defined by a subset of neural activity that constitutes a mental representation, and I concur with Gerlai's (2017) statement that "Mental representations imply that there is an actor, the self, that experiences, and plays a role in, the representation" (p. 2). If this implication is accepted, it is useful to assign to fishes what Baker (2013) calls a rudimentary first-person perspective. Baker's rudimentary first-person perspective is independent of linguistic or conceptual abilities and does not require self-consciousness. It only entails that a sentient subject is the origin in time and space of its perception of the environment.

\subsection{Neural correlates and the neuron doctrine}

My argument that fishes have the capacity for sentience and a rudimentary first-person perspective rests, in part, on the neurophysiological consequences of synaptic interactions among neurons. Pereira (2017a) rejects that synaptic interactions are solely responsible for, or perhaps even crucial for, generation of the bioelectrical correlates of sentience. Rather, he proposes that Golgi's syncytial model of the nervous system provides the physical substrate "at least for affective and motivational states" associated with sentience through generation of what he calls "hydro-ionic waves." Pereira's hypothesis necessitates significant revision of the neuron doctrine, a paradigm that has guided advances in neuroscientific research for more than a century. These advances include plausible hypotheses for the neural basis of the basic feeling states of sentience (Damasio 2010).

If a sufficient number of observations incompatible with the neuron doctrine were identified in the search for the neural correlates of sentience, then a revolutionary paradigm shift away from it might be justified (Kuhn 1970). However, whereas fusion of neuronal membranes, for example, may play a role in nervous system development and repair (Giordano-Santini et al. 2016), and astroglia may function to modulate bioelectric correlates of sentience (Pereira, Jr., 2017b; Pereira, Jr., et al. 2017), such observations fall short of what is needed for a Kuhnian paradigm shift.

\subsection{Neural correlates and structural homologies}

I noted in the first section of this Response that progress has been made in identifying potential neural correlates of sentience in humans. This has led to acceptance of the premise that the existence of at least some of these correlates can serve as an indicator of sentience in animals (e.g., Boly et al. 2013; Edelman et al. 2005; Seth et al. 2005). Following this premise, I proposed in the target article that some neuroanatomical and neurophysiological correlates 
of sentience associated with the human neocortex can be identified in the fish pallium. Several of the commentators took me to task for this (Husband; Mikhalevich; Stauffer).

I did not intend to argue that sentience absolutely requires the presence of structural homologies to the mammalian neocortex. Structures are commonly defined as homologous across taxa if common embryological origin, pattern of embryological development, and derivation from a common ancestor can be demonstrated. Similarity in function is not required. The function of homologous structures can obviously diverge during evolution and the same function can be caused by different structures, which is the case for brain structurefunction relationships across taxa. Thus, in response specifically to Burgos and Mikhalevich, I think it is plausible when theorizing about consciousness in fishes to adopt a limited functionalist approach. ${ }^{4}$ That is, any one of several neural structures might serve the same function; and flexibility in the pattern of underlying synaptic connectivity is possible. Thus, I agree with the quote from Braithwaite and Droege (2016) that Mikhalevich includes in her commentary: "the question is not whether fish have a cortex or an insula, but whether they have the functional capacity for (indicators of consciousness such as) global integration and attentional amplification."

A limited functionalist approach seems particularly appropriate to my sketch of a theory of sentience in fishes. On the one hand, the tectum is seen as having a primary role in the generation of sentience and the dorsodorsal (DD) pallium - which, I proposed, based on electrophysiological data, might function as an association area of the pallium - has no homology in the mammalian neocortex. On the other hand, the dorsolateral (DL) and dorsomedial (DM) pallium are structural homologs to the mammalian hippocampus and amygdala, respectively, and evidence exists that the DL and DM are also functionally analogous to these structures. For example, ablation of the hippocampus proper (Ammon's horn, the dentate gyrus, and the subiculum) impairs allocentric spatial learning in rats (Nadel 1991), as does ablation of DL in goldfish (Durán et al. 2010). Lesions of the rat amygdala or goldfish DM do not produce an impairment in spatial tasks. Conversely, destruction of the rat amygdala or goldfish DM, but not the hippocampus or DL, impairs two-way electric shock avoidance learning (Portavella et al. 2004) without impairing escape from shock.

The functional relationships inferred from ablation experiments may not, however, be as straightforward as they appear. For example, while the hippocampus proper is important in allocentric spatial learning (Nadel 1991), so are adjacent cortical areas, the parahippocampal and retrosplenial gyri (Ekstrom et al. 2014). These gyri connect with the anterior nucleus of the thalamus (AnTh), a structure which in mammals is associated with allocentric spatial learning (Aggleton et al. 2010; Jankowski et al. 2013). The hippocampus

\footnotetext{
${ }^{4}$ Burgos commented that these are "philosophical choppy waters." Indeed, they are. Here, I call this limited functionalism to give a name to an approach which maintains that sentience in animals requires some presently unknown minimal amount of neural tissue and complexity of neural circuitry, although both the gross and microscopic architecture of this neural tissue may differ significantly across taxa. Thus, I have rejected the theory that bacteria are sentient (Woodruff 2016) because the physical basis for their responses to the environment is explicable by reference to comparatively simple molecular interactions. Regarding computers, in response to Burgos, I accept the possibility that electronic circuitry sufficiently complex to produce machine sentience is, in principle, possible. So, I am open, in the case of computers, to an expanded view of functionalism. However, as recent publications indicate, whether computers are now, or can become, sentient remains controversial (e.g., Carter et al. 2017; Dehaene et al. 2018).
} 
proper does not have direct connections with AnTh, but the fish DL does (Echteler and Saidel 1981). Combined, these observations suggest that the DL may not be exactly equivalent to the hippocampus proper in mammals but may include anatomical and functional similarities to parts of the mammalian cortex including participation, as I propose, in sentience.

I suggest that this may apply to the DM as well. Taschereau-Dumouchel et al. expressed concern that I include the amygdala as part of the substrate for conscious experience of emotion in humans. I do not, but this does not rule out the possible participation of the DM in the conscious experience of emotion by fishes. As I noted in the target article, I base this possibility on the observation that DM lesions impair operant avoidance conditioning in fishes. Operant procedures have been used to separate reflex responses to nociceptive stimuli from appreciation of the felt sensation of pain in monkeys and rats (Morgan et al. 2008; Vierck, 2006). Disruption of operant shock-avoidance learning by DM lesions supports the hypothesis that the DM is involved in sentient appreciation of the emotional component of pain. The DM and other pallial regions may be more generally involved in the conscious experience of emotion. As Rey Planellas (2017) discusses in her commentary, pallial afferents from the hypothalamus and other subpallial structures that modulate behaviors associated with the emotional contents of sentience, such as emotional fever (Rey et al. 2015), have been found in fishes. These observations support my argument that the pallium participates in the conscious appreciation of the quality of exteroceptive and interoceptive stimuli.

Burgos questions the validity of proposing that any one neural structure or system is necessary for either the behaviors just discussed or for sentience. He suggests that J. L. Mackie's INUS-conditions (Insufficient, Nonredundant, Unnecessary, Sufficient) approach could be a better approach for defining causal relationships between brain structures and effects such as sentience than one that ascribes causation to activity within a set structure or group of structures in the brain. With INUS conditions, effects are caused by clusters of factors (e.g., A\&B\&C). An individual factor within the cluster is Insufficient to produce the effect, but the factors are Nonredundant. Any one of several different clusters (e.g., A\&B\&C or D\&E\&F or G\&H\&I) can produce the effect. Thus, a specific cluster is Unnecessary for the existence of the effect but is Sufficient to cause the effect. The INUS is compatible with functionalism. However, it is difficult to reconcile with data, such as those just described for the effects of DL and DM lesions in goldfish, which support the current consensus that distinct types of cognitive information are processed within distinct brain structures. It is also a poor match for the mosaic evolution hypothesis which seems to provide the best explanation for the functional modularity of the fish brain (e.g., Gonzalez-Voyer et al. 2009). Therefore, inasmuch that it is compatible with recovery of function after brain damage, the INUS approach has some appeal, but it is difficult to see how it can practically advance our understanding of the neural basis of sentience.

\subsection{Global availability of information and sentience in fishes}

Taschereau-Dumouchel et al. state that "consciousness has been associated with the global availability of information to different subsystems in the brain" and then ask: "Do fishes have such a mechanism for global broadcasting conscious information to various subparts of their brains?" As I discussed in the target article, feedforward and feedback excitatory neuronal circuitry capable of amplification of neural signals, as well as inhibitory circuits that serve to 
sharpen the information content of these signals, have been identified in the tectum and the pallium of fishes. Also, numerous connections among the several pallial divisions, and substantial afferent and efferent connections between the pallium and subpallial structures, including an analog of the mammalian thalamus, the preglomerular complex, exist. These connections can serve as the basis for reentrant processing. Thus, it is plausible to propose that the neuroanatomy of the fish brain is complex enough to foster the global availability of information that some theorize is necessary for sentience (e.g., Baars et al. 2013; Dehaene and Naccache 2001). Electrophysiological responses proposed to correlate with sensory binding and global broadcasting of sensory information (Baars et al. 2013; Crick and Koch, 2003) have also been recorded from the pallium. These responses include gamma frequency electrical rhythms (Prechtl et al., 1998) and sustained evoked responses to sensory stimulation (Elliot and Maler 2015; Prechtl et al., 1998).

Thus, it may be reasonable to conclude that global broadcasting of information to various sub-systems of the fish brain occurs. I think this conclusion is at best tentative, however. It is based on inference from the results of experiments conducted to test hypotheses related to sensory processing, learning and memory, and so forth. These experiments were not designed to separate the neural correlates of cognitive processing supporting these functions from the neural correlates of global information broadcasting. While the similarities between fish neuroanatomy and neurophysiology and some neural correlates of consciousness in humans are intriguing, the conclusion that global broadcasting of information occurs in the fish brain relies on post-hoc interpretation of the data. The conclusion also assumes that Baars's (1988) global workspace model of consciousness is valid for humans. Even if this is the case, within the limited functionalist approach I propose, there is no reason to assume that the global workspace model must be relevant to sentience in fishes.

\section{CONCLUSIONS}

In the target article, I offered a sketch of what Burgos correctly refers to as a "highly heuristic" theory. I proposed that the fish pallium participates in the elaboration of sentience, that is, the subjective awareness of interoceptive and exteroceptive sense impressions, and that it does this as part of a reentrant network of neural structures that is centered on the tectum and includes the preglomerular complex. I did not claim that the fish pallium is closely homologous to that of mammals, although I did argue that the fish pallium shares some of the organizational principles thought to be correlated with sentience in humans.

I stand by the claims I made in the target article. However, to advance beyond a heuristic sketch of a theory of the neural basis of fish sentience, hypotheses and experiments that are specifically directed towards this problem will have to be developed. Given that we do not have direct access to the contents of sentient states in fish (or, for that matter, sentient states in any being other than ourselves), this is clearly a challenge. If this challenge is to be met, a behavioral battery that can serve as a "Turing test" for fish sentience (Gerlai) must be agreed upon. As Braithwaite (2010), Brown (2014; 2017) and Gerlai discuss, there are numerous candidates for inclusion in this battery. Appropriately designed electrophysiological experiments will also have to be conducted. These experiments might, for example, look for differences in neural activity between behaviors included in the Turing test battery and those behaviors that had been ruled out. Finally, it would be well to keep in 
mind that, as Gerlai states, "to truly understand what it feels like to be a fish, we may need to appreciate both the similarities and the differences between us and them. We may even need a better understanding of what it really feels like to be human" (p. 3).

\section{References}

Aggleton, J. P., O’Mara, S. M., Vann, S. D., Wright, N. F., Tsanov, M. and Erichsen, J. T. (2010). Hippocampal-anterior thalamic pathways for memory: uncovering a network of direct and indirect actions. European Journal of Neuroscience, 31, 2292-2307.

Allen, C. and Trestman, M. (2016). Animal consciousness. In E. N. Zalta (Ed.), The Stanford encyclopedia of philosophy (Winter Edition).

Allen-Hermanson, S. (2017). Battlefish contention. Animal Sentience 13(3).

Andrews, K. (2015). Animal minds: an introduction to the philosophy of animal cognition. New York, NY: Routledge.

Baars, B. J. (1988). A cognitive theory of consciousness. New York, NY: Cambridge University Press.

Baars, B. J., Franklin, S. and Ramsoy, T. Z. (2013). Global workspace dynamics: cortical "binding and propagation" enables conscious contents. Frontiers in Psychology, 4, 200.

Baddeley, A. D. (1986). Working memory. Oxford, UK: Oxford University Press.

Baker, L. R. (2013). Naturalism and the first-person perspective. New York, NY: Oxford University Press.

Balcombe, J. (2016). In praise of fishes: précis of What a fish knows. Animal Sentience 8(1). Birch, J. (2017). Animal sentience and the precautionary principle. Animal Sentience 16(1).

Block, N. (1995). On a confusion about a function of consciousness. Behavioral and Brain Sciences, 18, 227-287.

Block, N. (2007). Consciousness, accessibility, and the mesh between psychology and neuroscience. Behavioral and Bran Sciences, 30, 481-499.

Block, N. (2011). Perceptual consciousness overflows cognitive access. Trends in Cognitive Sciences, 15, 567-575.

Boly, M., Seth, A. K., Wilke, M., Ingmundson, P., Baars, B., Laureys, S., Edelman, D. B. and Tsuchiya, N. (2013). Consciousness in humans and non-human animals: recent advances and future directions. Frontiers in Psychology, 31.

van Boxtel, J. J. A., Tsuchiya, N. and Koch, C. (2010). Consciousness and attention: on sufficiency and necessity. Frontiers in Psychology, 1, 217.

Braithwaite, V. A. (2010). Do fish feel pain? Oxford, UK: Oxford University Press.

Braithwaite, V. A. and Droege, P. (2016). Why human pain can't tell us whether fish feel pain. Animal Sentience 3(3).

Brown, C. (2014). Fish intelligence, sentience and ethics. Animal Cognition, 18, 1-17.

Brown, C. (2017). A risk assessment and phylogenetic approach. Animal Sentience 16(3).

Burgos, J. E. (2017). Fish sentience: A hypothesis worth pursuing. Animal Sentience 13(12).

Carter, O., Hohwy, J., van Boxtel, J., Lamme, V., Block, N., Koch, C. and Tsuchiya, N. (2018). Conscious machines: defining questions. Science, 395, 400.

Cohen, M. A., Cavanagh, P., Chun, M. A. and Nakayama, K. (2012). The attentional requirements of consciousness. Trends in Cognitive Sciences, 16, 411-417. 
Costall, A. P. (1984). Are theories of perception necessary? A review of Gibson's the ecological approach to visual perception. Journal of the Experimental Analysis of Behavior, 41, 109-115.

Creson, T. (2017). Animal models, agendas and sentience. Animal Sentience 13(10).

Creson, T. K., Woodruff, M. L., Ferslew, K. E., Rasch, E. M. and Monaco, P. J. (2003). Dose response effects of chronic lithium regimen on spatial memory in the black molly fish. Pharmacology, Biochemistry and Behavior, 75, 35-47.

Crick, F. and Koch, C. (2003). A framework for consciousness. Nature Neuroscience, 6, 119126.

Damasio, A. R. (2010). Self comes to mind: constructing the conscious mind. New York, NY: Pantheon Books.

Dehaene, S. (2014). Consciousness and the brain: deciphering how the brain codes our thoughts. New York, NY: Penguin Publishing Group.

Dehaene, S. and Naccache, L. (2001). Towards a cognitive neuroscience of consciousness: basic evidence and a workspace framework. Cognition, 79, 1-37.

Dehaene, S., Changeux, J. P., Naccache, L., Sackur, J. and Sergent, C. (2006). Conscious, preconscious, and subliminal processing: a testable taxonomy. Trends in Cognitive Science, 10, 204-211.

Dehaene, S., Lau, H. and Kouider, S. (2018). What is consciousness, and could machines have it? Science, 358, 486-492.

Douglas, H. (2000). Inductive risk and values in science. Philosophy of Science, 67, 559-579.

Douglas, H. (2009). Science, policy, and the value-free ideal. Pittsburgh, PA: University of Pittsburgh Press.

Droege, P. (2017). We still need a theory. Animal Sentience 13(13).

Droege, P. and Braithwaite, V. A. (2014). A framework for investigating animal consciousness. Current Topics in Behavioral Neuroscience, 19, 79-98.

Dudchenko, P. A. (2004). An overview of the tasks used to test working memory in rodents. Neuroscience and Biobehavioral Reviews, 28, 699-709.

Durán, E., Ocaña, F. M., Broglio, C., Rodríguez, F. and Salas, C. (2010). Lateral but not medial telencephalic pallium ablation impairs the use of goldfish spatial allocentric strategies in a "hole-board" task. Behavioural Brain Research, 214, 480-487.

Echteler, S. M. and Saidel, W. M. (1981). Forebrain connections in the goldfish support telencephalic homologies with land vertebrates. Science, 212, 683-685.

Edelman, D. B., Baars, B. J. and Seth, A. (2005). Criteria for consciousness in humans and other mammals. Consciousness and Cognition, 14, 169-187.

Edelman, G. M. (1989). The remembered present: a biological theory of consciousness. New York, NY: Basic Books.

Edelman, G. M. (2003). Naturalizing consciousness: a theoretical framework. Proceedings of the National Academy of Sciences U.S.A., 100, 5520-5524.

Eichenbaum, H. (2000). A cortical-hippocampal system for declarative memory. Nature Reviews Neuroscience, 1, 41-50.

Ekstrom, A. D., Arnold, E. G. F. and Iaria, G. (2014). A critical review of the allocentric spatial representation and its neural underpinnings: toward a network-based perspective. Frontiers in Human Neuroscience, 9, 803.

Elliott, S. and Maler, L. (2015). Stimulus-induced up states in the dorsal pallium of a weakly electric fish. Journal of Neurophysiology, 114, 2071-2076. 
Favela, L. H. (2017). Mental representations are not necessary for fish consciousness. Animal Sentience 13(9).

Feinberg, T. E. and Mallatt, J. M. (2016). The ancient origins of consciousness: how the brain created experience. Cambridge, MA: MIT Press.

Gerlai, R. (2017). Learning, memory, cognition, and the question of sentience in fish. Animal Sentience 13(8).

Giacino, J. T., Fins, J. J., Laureys, S. and Schiff, N. D. (2014). Disorders of consciousness after acquired brain injury: the state of the science. Nature Reviews Neurology, 10, 99-114.

Gibson, J. J. (1979). The ecological approach to visual perception. Boston, MA: Houghton Mifflin.

Gilman, D. (1997). Consciousness and mental representation. Behavioral and Brain Sciences, 20, 150-151.

Giordano-Santini, R., Linton, C. and Hilliard, M. A. (2016). Cell-cell fusion in the nervous system: Alternative mechanisms of development, injury, and repair. Seminars in Cell \& Developmental Biology, 60, 146-154.

Gonzalez-Voyer, A., Winberg, S. and Kolm, N. (2009). Brain structure evolution in a basal vertebrate clade: evidence from phylogenetic comparative analysis of cichlid fishes. $B M C$ Evolutionary Biology, 9, 238.

Gosseries, O., Di, H., Laureys, S. and Boly, M. (2014). Measuring consciousness in severely damaged brains. Annual Review of Neuroscience, 37, 457-478.

Grosenick, L., Clement, T. S. and Fernald, R. D. (2007). Fish can infer social rank by observation alone. Nature, 445, 429-432.

Gutfreund, Y. (2017a). Animal sentience? Neuroscience has no answers. Animal Sentience $13(4)$.

Gutfreund, Y. (2017b). The neuroethological paradox of animal consciousness. Trends in Neuroscience, 40, 196-199.

Güzelderea, G. and Aydedeb, M. (1997). On the relation between phenomenal and representational properties. Behavioral and Brain Sciences, 20, 151-153.

Husband, S. A. (2017). Of cortex and consciousness: "phenomenal," "access," or otherwise. Animal Sentience 13(7).

Jankowski, M. M., Ronnqvist, K. C., Tsanov, M., Vann, S. D., Wright, N. F., Erichsen, J. T., Aggleton, J. P. and O'Mara, S. M. (2013). The anterior thalamus provides a subcortical circuit supporting memory and spatial navigation. Frontiers in Systems Neuroscience, 7, 45.

Johnston, W. A. and Dark, V. J. (1986). Selective attention. Annual Reviews in Psychology, 37, 43-75.

Koch, C. (2012). Consciousness: confessions of a romantic reductionist. Cambridge, MA: The MIT Press.

Koch, C. and Tsuchiya, N. (2007). Phenomenology without conscious access is a form of consciousness without top-down attention. Behavioral and Bran Sciences, 30, 509-510.

Kuhn, T. S. (1970). The structure of scientific revolutions (2nd Edition, Enlarged). Chicago, IL: University of Chicago Press.

LaFollette, H. (2017). Nagel-ing worries about fish sentience. Animal Sentience 13(6).

Laureys, S. and Schiff, N. D. (2012). Coma and consciousness: paradigms (re)framed by neuroimaging. Neuroimage, 61, 478-491. 
Mack, A., Erol, M. and Jason Clarke, J. (2015). Iconic memory is not a case of attention-free awareness. Consciousness and Cognition, 33, 291-299.

Mack, A., Erol, M., Clarke, J. and Bert, J. (2016). No iconic memory without attention Consciousness and Cognition, 40, 1-8.

Mangan, B. (1997). Empirical status of Block's phenomenal/access distinction. Behavioral and Brain Sciences, 20, 153-154.

Merker, B. (2007). Consciousness without a cerebral cortex: a challenge for neuroscience and medicine. Behavioral and Brain Sciences, 30, 63-81.

Mikhalevich, I. (2017). Consciousness, evidence, and moral standing. Animal Sentience 13(2).

Miller, G. A., Galanter, E. and Pribram, K. H. (1960). Plans and the structure of behavior. New York, NY: Holt, Rinehart and Winston.

Morgan, D., Carter, C. S., DuPree, J. P., Yezierski, R. P. and Vierck, C. J., Jr. (2008). Evaluation of prescription opioids using operant-based pain measures in rats. Experimental and Clinical Psychopharmacology, 16, 367-375.

Naccachea, L. and Dehaene, S. (2007). Reportability and illusions of phenomenality in the light of the global neuronal workspace model. Behavioral and Bran Sciences, 30, 518520.

Nadel, L. (1991). The hippocampus and space revisited. Hippocampus, 1, 221-229.

Nilsson, J., Kristiansen, T. S., Fosseidengen, J. E., Fernö, A. and van den Bos, R. (2008). Learning in cod (Gadus morhua): long trace interval retention. Animal Cognition, 11, 215-222.

Nilsson, J., Kristiansen, T. S., Fosseidengen, J. E., Stien, L. H., Fernö, A. and van den Bos, R. (2010). Learning and anticipatory behaviour in a "sit-and-wait" predator: the Atlantic halibut. Behavioral Processes, 83, 257-266.

Noë, N. (1997). Perception and content. Behavioral and Brain Sciences, 20, 154-155.

Ohnishi, K. (1974). Effects of telencephalic ablation on short-term memory and attention in goldfish. Behavioural Brain Research, 86, 191-199.

Olton, D. S., Becker, J. T. and Handelmann, G. E. (1979). Hippocampus, space, and memory. Behavioral Brain Sciences, 2, 313-365.

Papineau, D. (2007). Reuniting (scene) phenomenology with (scene) access. Behavioral and Bran Sciences, 30, 521.

Pereira, A., Jr. (2017a). Sentience in living tissue. Animal Sentience 13(5).

Pereira, A., Jr. (2017b). Astroglial hydro-ionic waves guided by the extracellular matrix: an exploratory model. Journal of Integrative Neuroscience, 16, 1-16.

Pereira, A., Jr., Foz, F. B. and da Rocha, A. F. (2017). The dynamical signature of conscious processing: from modality-specific percepts to complex episodes. Psychology of Consciousness: Theory, Research, and Practice, 4, 230-247.

Persuh, M., Genzer, B. and Melara, R. D. (2012). Iconic memory requires attention. Frontiers in Human Neuroscience, 6, 126.

Portavella, M., Torres, B. and Salas, C. (2004). Avoidance response in goldfish: emotional and temporal involvement of medial and lateral telencephalic pallium. The Journal of Neuroscience, 24, 2335-2342.

Prechtl, J. C., von der Emde, G., Wolfart, J., Karamürsel, S., Akoev, G. N., Andrianov, Y. N. and Bullock, T. H. (1998). Sensory processing in the pallium of a mormyrid fish. Journal of Neuroscience, 18, 7381-7393. 
Prinz, J. J. (2000). A neurofunctional theory of visual consciousness. Consciousness and Cognition, 9, 243-259.

Rey Planellas, S. (2017). The emotional brain of fish. Animal Sentience 13(11).

Rey, S., Huntingford, F. A., Boltana, S., Vargas, R., Knowles, T. G. and Mackenzie, S. (2015). Fish can show emotional fever: stress-induced hyperthermia in zebrafish. Proceedings of the Royal Society, 282, 20152266.

Roitblat, H. L., Tham, W. and Golub, L. (1982). Performance of Betta splendens in a radial maze. Animal Learning and Behavior, 10, 108-114.

Seth, A. K., Baars, B. J. and Edelman, D. B. (2005). Criteria for consciousness in humans and other mammals. Consciousness and Cognition, 14, 119-139.

Simons, D. J. and Levin, D. T. (1997). Change blindness. Trends in Cognitive Sciences, 1(7), 261-267.

Sperling, G. (1960). The information available in brief visual presentations. Psychological Monographs, 74, 1-29.

Stauffer, J. R., Jr. (2017). Similar anatomy does not imply comparable function. Animal Sentience 13(14).

Storm, J. F., Boly, M., Casali, A. G., Massimini, M., Olcese, U., Pennartz, C. M. A. and Wilke, M. (2017). Consciousness regained: disentangling mechanisms, brain systems, and behavioral responses. The Journal of Neuroscience, 37, 10882-10893.

Taschereau-Dumouchel, V., Grimaldi, P. and Lau, H. (2017). Can unconscious brain processes indicate sentience? Animal Sentience 13(15).

Vargas, J. P., López, J. C. and Portavella, M. (2009). What are the functions of fish brain pallium? Brain Research Bulletin, 79, 436-440.

Vierck, C. J., Jr. (2006). Animal models of pain. In S. B. McMahon and M. Koltzenburg (Eds.), Wall and Melzack's textbook of pain (Vol. 5). London: Elsevier, 175-185.

White, G. E. and Brown C. (2015). Cue choice and spatial learning ability are affected by habitat complexity in intertidal gobies. Behavioral Ecology, 26, 178-184.

Woodruff, M. L. (2016). Bacteria and the cellular basis of consciousness. Animal Sentience $11(2)$.

Woodruff, M. L. (2017). Consciousness in teleosts: there is something it feels like to be a fish. Animal Sentience 13(1).

Woodruff, M. L., Baisden, R. H. and Cannon, R. L. (1993). Transplant-induced deficits in working memory in hippocampal-damaged rats. Physiology \& Behavior, 54, 579-587.

Woodruff, M. L., Nonneman, A. J. and Baisden, R. H. (1992). Effects of transplantation of fetal hippocampal or hindbrain tissue into the brains of adult rats with hippocampal lesions on water-maze acquisition. Behavioral Neuroscience, 106, 39-50. 


\section{UQÀM/ISC Cognitive Science Summer School June 26 - July 6 2018, Montreal, Canada}

\section{The Other Minds Problem: Animal Sentience and Cognition}

Overview. Since Descartes, philosophers know there is no way to know for sure what - or whether - others feel (not even if they tell you). Science, however, is not about certainty but about probability and evidence. The 7.5 billion individual members of the human species can tell us what they are feeling. But there are 9 million other species on the planet (20 quintillion individuals), from elephants to jellyfish, with which humans share biological and cognitive ancestry, but not one other species can speak: Which of them can feel - and what do they feel? Their human spokespersons - the comparative psychologists, ethologists, evolutionists, and cognitive neurobiologists who are the world's leading experts in "mind-reading" other species -- will provide a sweeping panorama of what it feels like to be an elephant, ape, whale, cow, pig, dog, bat, chicken, fish, lizard, lobster, snail: This growing body of facts about nonhuman sentience has profound implications not only for our understanding of human cognition, but for our treatment of other sentient species.

\begin{tabular}{|c|}
\hline $\begin{array}{l}\text { Gregory Berns: Decoding the Dog's Mind with Awake } \\
\text { Neuroimaging }\end{array}$ \\
\hline Gordon Burghardt: Probing the Umwelt of Reptiles \\
\hline Jon Sakata: Audience Effects on Communication Signals \\
\hline PANEL: Reptiles, Birds and Mammals \\
\hline $\begin{array}{l}\text { WORKSHOP: Kristin Andrews: The "Other" Problems: } \\
\text { Mind, Behavior, and Agency }\end{array}$ \\
\hline $\begin{array}{l}\text { Sarah Brosnan: How Do Primates Feel About Their Social } \\
\text { Partners? }\end{array}$ \\
\hline Alexander Ophir: The Cognitive Ecology of Monogamy \\
\hline $\begin{array}{l}\text { Michael Hendricks: Integrating Action and Perception in a } \\
\text { Small Nervous System }\end{array}$ \\
\hline PANEL: Primates, Voles and Worms \\
\hline $\begin{array}{l}\text { WORKSHOP: Jonathan Birch: Animal Sentience and the } \\
\text { Precautionary Principle }\end{array}$ \\
\hline $\begin{array}{l}\text { Malcolm MacIver: How Sentience Changed After Fish } \\
\text { Invaded Land } 385 \text { Million Years Ago }\end{array}$ \\
\hline $\begin{array}{l}\text { Sarah Woolley: Neural Mechanisms of Preference in } \\
\text { Female Songbird }\end{array}$ \\
\hline $\begin{array}{l}\text { Simon Reader: Animal Social Learning: Implications for } \\
\text { Understanding Others }\end{array}$ \\
\hline PANEL: Sea to Land to Air \\
\hline WORKSHOP: Steven M. Wise: Nonhuman Personhood \\
\hline $\begin{array}{l}\text { Tomoko Ohyama: Action Selection in a Small Brain } \\
\text { (Drosophila Maggot) }\end{array}$ \\
\hline $\begin{array}{l}\text { Mike Ryan: "Crazy Love": Nonlinearity and Irrationality in } \\
\text { Mate Choice }\end{array}$ \\
\hline $\begin{array}{l}\text { Louis Lefebvre: Animal Innovation: From Ecology to } \\
\text { Neurotransmitters }\end{array}$ \\
\hline PANEL: Maggots, Frogs and Birds: Flexibility Evolving \\
\hline SPECIAL EVENT: Mario Cyr: Polar Bears \\
\hline $\begin{array}{l}\text { Colin Chapman: Why Do We Want to Think People Are } \\
\text { Different? }\end{array}$ \\
\hline Vladimir Pradosudov: Chickadee Spatial Cognition \\
\hline Jonathan Balcombe: The Sentient World of Fishes \\
\hline PANEL: Similarities and Differences \\
\hline $\begin{array}{l}\text { WORKSHOP (part 1): Gary Comstock: A Cow's Concept } \\
\text { of Her Future }\end{array}$ \\
\hline $\begin{array}{l}\text { WORKSHOP (part 2): Jean-Jacques Kona-Boun: } \\
\text { Physical and Mental Risks to Cattle and Horses in Rodeos }\end{array}$ \\
\hline
\end{tabular}

\begin{tabular}{|c|}
\hline $\begin{array}{l}\text { Joshua Plotnik: Thoughtful Trunks: Application of } \\
\text { Elephant Cognition for Elephant Conservation }\end{array}$ \\
\hline Lori Marino: Who Are Dolphins? \\
\hline PANEL: Mammals All, Great and Small \\
\hline $\begin{array}{l}\text { Larry Young: The Neurobiology of Social Bonding, } \\
\text { Empathy and Social Loss in Monogamous Voles }\end{array}$ \\
\hline $\begin{array}{l}\text { WORKSHOP: Lori Marino: The Inconvenient Truth } \\
\text { About Thinking Chickens }\end{array}$ \\
\hline $\begin{array}{l}\text { Andrew Adamatzky: Slime Mould: Cognition Through } \\
\text { Computation }\end{array}$ \\
\hline $\begin{array}{l}\text { Frantisek Baluska \& Stefano Mancuso: What a Plant } \\
\text { Knows and Perceives }\end{array}$ \\
\hline $\begin{array}{l}\text { Arthur Reber: A Novel Theory of the Origin of Mind: } \\
\text { Conversations With a Caterpillar and a Bacterium }\end{array}$ \\
\hline PANEL: Microbes, Molds and Plants \\
\hline $\begin{array}{l}\text { WORKSHOP: Suzanne Held \& Michael Mendl: Pig } \\
\text { Cognition and Why It Matters }\end{array}$ \\
\hline James Simmons: What Is It Like To Be A Bat? \\
\hline Debbie Kelly: Spatial Cognition in Food-Storing \\
\hline Steve Phelps: Social Cognition Across Species \\
\hline PANEL \\
\hline WORKSHOP: To be announced \\
\hline Lars Chittka: The Mind of the Bee \\
\hline $\begin{array}{l}\text { Reuven Dukas: Insect Emotions: Mechanisms and } \\
\text { Evolutionary Biology }\end{array}$ \\
\hline $\begin{array}{l}\text { Adam Shriver: Do Human Lesion Studies Tell Us the } \\
\text { Cortex is Required for Pain Experiences? }\end{array}$ \\
\hline PANEL \\
\hline $\begin{array}{l}\text { WORKSHOP: Delcianna Winders: Nonhuman Animals } \\
\text { in Sport and Entertainment }\end{array}$ \\
\hline $\begin{array}{l}\text { Carel ten Cate: Avian Capacity for Categorization and } \\
\text { Abstraction }\end{array}$ \\
\hline Jennifer Mather: Do Squid Have a Sense of Self? \\
\hline $\begin{array}{l}\text { Steve Chang: Neurobiology of Monkeys Thinking About } \\
\text { Other Monkeys }\end{array}$ \\
\hline PANEL \\
\hline $\begin{array}{l}\text { WORKSHOP: The Legal Status of Sentient Nonhuman } \\
\text { Species }\end{array}$ \\
\hline
\end{tabular}

